\title{
ЕЛЕКТРИЧНІ І ОПТИЧНІ ВЛАСТИВОСТІ МОНОКРИСТАЛІВ $\mathrm{AgGaGe}_{2} \mathrm{~S}_{2} \mathrm{Se}_{4}$
}

\author{
Г.Л. МИРОНЧУК, Г.Є. ДАВИДЮК, О.В. ПАРАСЮК, М.В. ШЕВЧУК, \\ О.В. ЯКИМЧУК, С.П. ДАНИЛЬЧУК
}

\begin{abstract}
Досліджено монокристали твердих розчинів 50 мол.\% $\mathrm{AgGaGeS}_{4}$ +50 мол.\% $\mathrm{AgGaGe} \mathrm{Se}_{8}$. Внаслідок статистичного розміщення у вузлах кристалічної гратки атомів $\mathrm{Ga}$ i Ge, а також наявності вузлів не заповнених атомами $\mathrm{Ag}$, тверді розчини проявляють властивості невпорядкованих напівпровідників з максимальною щільністю локалізованих енергетичних станів біля середини забороненої зони. Встановлено оптичну і термічну ширину забороненої зони та їх температурну залежність $\left(E_{g} \approx 2,30 \mathrm{eB}\right.$ при $T \approx 300 \mathrm{~K})$. Монокристали розчину $\mathrm{AgGaGe}_{2} \mathrm{Se}_{4}$ виявилися фоточутливими напівпровідниками $p$-типу провідності 3 положенням рівня Фермі біля середини забороненої зони. Досліджено особливості електропровідності і спектрального розподілу фотопровідності зразків розчину. Запропоновано несуперечливу фізичну модель, яка дозволяє пояснити експериментально одержані результати.
\end{abstract}

\section{1. Вступ}

На даний час одними із найбільш поширених матеріалів для параметричної генерації світла середнього IЧдіапазону є монокристали тернарних сполук $\mathrm{AgGaS}_{2}$ i $\mathrm{AgGaSe}_{2}$. Основні споживачі параметричних кристалів потужні CO- і $\mathrm{CO}_{2}$-лазери. Тетрарні сполуки $\mathrm{AgGaGeS}_{4}$ i $\mathrm{AgGaGe}_{3} \mathrm{Se}_{8}$ є аналогами $\mathrm{AgGaS}_{2}$ i $\mathrm{AgGaSe}_{2}$, були знайдені при спробі покращити параметри тернарних фаз шляхом додавання дихалькогенідів германію. Поряд із вдвічі більшою стійкістю до дії лазерного випромінювання, у них зростає величина двопроменезаломлення, збільшується область прозорості, а також зменшується температура плавлення тетрарних сполук, що позитивно впливає на технологію одержання якісних кристалів. $\mathrm{AgGaGeS}_{4}$ i $\mathrm{AgGaGe}_{3} \mathrm{Se}_{8}$ є ізоструктурними та утворюють неперервний ряд твердих розчинів (НРТР) [1]. Фаза $\mathrm{AgGaGe}_{2} \mathrm{~S}_{2} \mathrm{Se}_{4}$ є частиною цього НРТР із вмістом 50 мол.\% $\mathrm{AgGaGe}_{3} \mathrm{Se}_{8}$. Для росту її кристалів нами використовувався метод Бріджмена-Стокбаргера. Температура зони росту двозонної печі становила 1170 K, а зони відпалу - $750 \mathrm{~K}$, які створювали градієнт температур на фронті кристалізації 3 K/мм. Відпал кристала тривав 200 годин, після якого проводилося його охолодження до кімнатної температури із швидкістю $5 \mathrm{~K} /$ год. Одержані таким способом монокристали були світло-червоного кольору. Їх середні розміри становили 35 мм в довжину та 9 мм у діаметрі.

Рентгеноструктурні дослідження показали, що кристали фази $\mathrm{AgGaGe} \mathrm{S}_{2} \mathrm{Se}_{4}$ належать до просторової групи $F d d 2 ; a=1,22746(5)$ нм, $b=2,3541(1)$ нм, $c=0,70539$ нм. У структурі атоми сульфуру та селену займають три шістнадцятикратні позиції $16 b$ у співвідношенні 1:1. При цьому, в такій же позиції, яка зайнята на 56,3\%, розміщені атоми Ag. Атоми Ga i Ge статистично розміщуються у двох кристалографічних позиціях $8 a$ та $16 b$, кожна з яких зайнята на $37,5 \%$ і $62,5 \%$ ними відповідно. Статистичний розподіл атомів $\mathrm{Ga}$ і Ge в кристалічній гратці твердого розчину $\mathrm{AgGaGe} \mathrm{S}_{2} \mathrm{Se}_{4}$ приводить до випадкової флуктуації електричного потенціалу і наближає його до невпорядкованого стану [2].

\section{2. Експериментальні результати та їх обговорення}

$\mathrm{y}$ роботі досліджували деякі електричні, оптичні і фотоелектричні властивості одержаних нами монокристалів $\mathrm{AgGaGe}_{2} \mathrm{~S}_{2} \mathrm{Se}_{4}$, які відносяться до високоомних речовин 3 темновою питомою електропровідністю $(\sigma)$ при кімнатній температурі $(T \approx 293 \mathrm{~K})$ рівною $\sigma \approx 2 \cdot 10^{-8} \mathrm{OM}^{-1} \mathrm{~cm}^{-1}$. Малі значення коефіцієнта термо-е.p.c. $(\alpha \approx 10-20 \mathrm{mkB} / \mathrm{K})$ і $\sigma$ свідчать про глибоке положення рівня Фермі $\left(E_{\mathrm{F}}\right)$, а саме, біля середини забороненої зони розчинів з близькими внесками в $\alpha$ електронної і діркової складової [3]:

$\alpha=\frac{\alpha_{p} \mu_{p} p-\alpha_{n} \mu_{n} n}{\mu_{p} p+\mu_{n} n}$,

де $\mu_{p}, \mu_{n}$ - рухливості дірок і електронів в зонах; $n, p$ - концентрація дірок і електронів; $\alpha_{p}, \alpha_{n}$ - парціальні коефіцієнти термо-е.p.c.

Оскільки для більшості напівпровідникових матеріалів $\mu_{p}$ менше $\mu_{n}$, то невелике додатне значення 


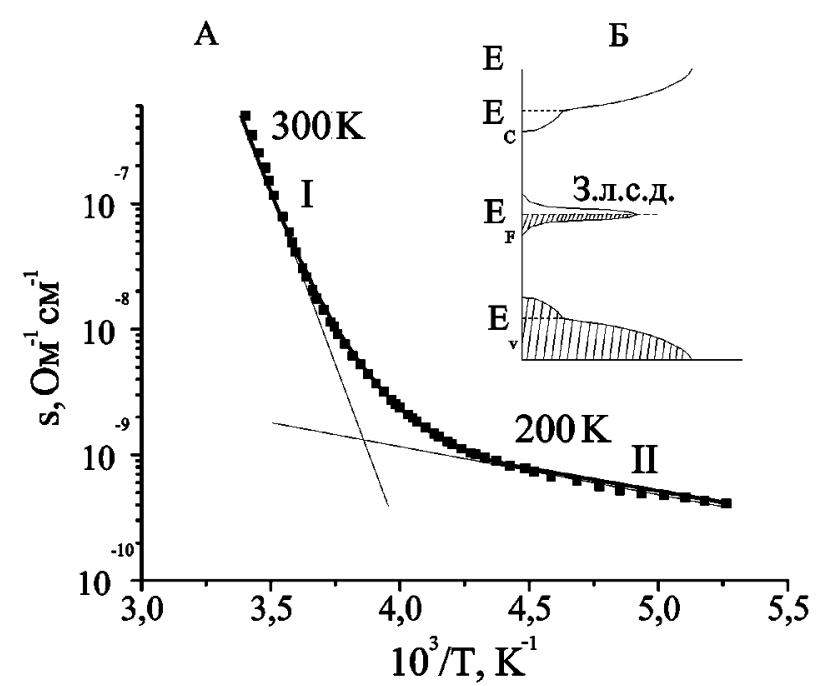

Рис. 1. Температурна залежність питомої електропровідності монокристалів $\mathrm{AgGaGe}_{2} \mathrm{~S}_{2} \mathrm{Se}_{4}(a)$; модель розподілу електронних дефектних станів у невпорядкованому напівпровіднику (за Девісом і Моттом) (б): $E_{c}$ і $E_{\nu}$ - граничні енергії, які розділяють локалізовані і нелокалізовані стани, з.л.с.д. - зона локалізованих домішкових станів

$\alpha$, що свідчить про $p$-тип провідності $\mathrm{AgGaGe}_{2} \mathrm{~S}_{2} \mathrm{Se}_{4}$, зумовлене, очевидно, деякою перевагою концентрації дірок над концентрацією електронів.

На рис. 1 наведено температурну залежність темнової питомої електропровідності $\sigma(T)$ монокристалів $\mathrm{AgGaGe}_{2} \mathrm{~S}_{2} \mathrm{Se}_{4}$. Як видно із рисунка, в різних температурних інтервалах (I і II) можна представити експоненціальною залежністю, що характерно для невпорядкованих напівпровідників [4]:

$\sigma=\sigma_{0} \exp \left(-\frac{E_{A}}{k T}\right)$.

Визначена із залежності (2) енергія активації електропровідності в області I $(T>270 \mathrm{~K})$ становить $E_{A \mathrm{I}} \approx(1,14 \pm 0,03) \mathrm{eB}$.

$\mathrm{y}$ дефектних кристалах внаслідок випадкового розподілу потенціалу електричного поля, зумовленого статичним розподілом атомів $\mathrm{Ga}$ i Ge в вузлах кристалічної гратки розчину і флуктуацією концентрації заряджених структурних дефектів, виникають хвости щільності електронних станів, які примикають до країв зон дозволених енергій і створюють зони дефектних локалізованих станів у забороненій зоні з настільки високою щільністю станів, що закріплюють рівень Фермі [4] (рис. 1,б). Значення передекспоненціального множника при $T \geq 270 \mathrm{~K}$ виявилося рівним $\sigma_{01} \approx 5 \cdot 10^{2}-10^{3} \mathrm{OM}^{-1} \cdot \mathrm{cm}^{-1}$ для різних кристалів, що свідчить згідно з моделлю електронних станів невпо-

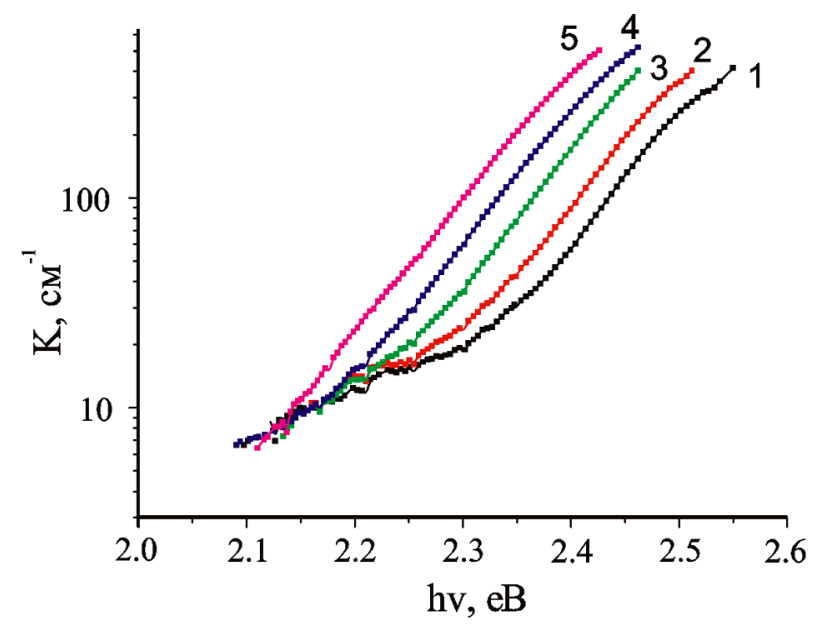

Рис. 2. Спектри оптичного поглинання світла в монокристалах $\mathrm{AgGaGe}_{2} \mathrm{~S}_{2} \mathrm{Se}_{4}$ при температурах: 1 - $100 \mathrm{~K}$; 2 - $150 \mathrm{~K}$; 3 - 200 $\mathrm{K} ; 4-250 \mathrm{~K} ; 5-300 \mathrm{~K}$

рядкованих систем [4] про термозбудження дірок із рівнів, які лежать близько рівня $E_{\mathrm{F}}$, в нелокалізовані стани валентної зони. Вважаючи, що рівень Фермі лежить біля середини забороненої зони (рис. 1,б), що випливає, як зазначалось вище, із малого значення $\alpha$ і низької електропровідності зразків (компенсовані), можна оцінити термічну ширину забороненої зони, яка виявилася рівною $E_{g T} \approx 2 E_{A \mathrm{I}}=(2,28 \pm 0,03) \mathrm{eB}$.

На низькотемпературній ділянці $T<200 \mathrm{~K}$ (II) енергія активації електропровідності має значення $E_{A \mathrm{II}} \approx(0,07 \pm 0,03)$ еВ, при цьому передекспоненціальний множник становив $\sigma_{0 \text { II }} \ll \sigma_{0 I}$. Така залежність $\sigma(T)$ характерна для стрибкової провідності між найближчими сусідами по домішковій дефектній зоні, яка закріплює $E_{\mathrm{F}}$. Енергія активації перескоків $E_{A \text { II }}$ близька до половини ширини зони локалізованих дефектних станів [4].

Важливу інформацію про дефектний стан напівпровідника дає дослідження частотної залежності коефіцієнта поглинання $(K(\nu))$ на краю смуги власного поглинання світла (КП). Як видно із рис. $2, K(\nu)$ в області КП добре описується експоненціальною залежністю, яку часто називають правилом Урбаха [2]:

$K(\nu) \sim \exp \left(-\frac{E_{g}-h \nu}{\Delta_{0}}\right)$

Виконання залежності (3) свідчить про те, що оптичні переходи в області краю власного поглинання світла формуються за участю хвостів щільності станів (зумовлених дефектністю кристала), які примикають до країв дозволених зон [2]. 


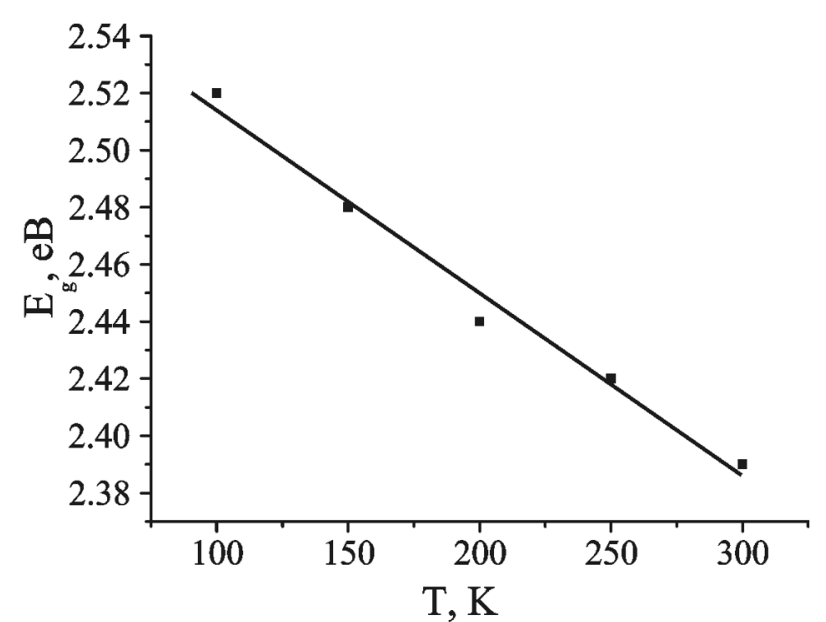

Рис. 3. Температурна зміна ширини забороненої зони монокристалів $\mathrm{AgGaGe}_{2} \mathrm{~S}_{2} \mathrm{Se}_{4}$

Розрахована із експоненціальної залежності (3) характеристична енергія, яка відповідає за ступінь розупорядкування кристалічної гратки становила $\sim 0,07$ eB (як в аморфних напівпровідниках [5]) і не змінювалась в температурному інтервалі 77-300 K, що зумовлює паралельне зміщення КП при зміні температури зразка (рис. 2). Велике значення $\Delta_{0}$ i його температурна незалежність свідчать про значну дефектність монокристалів $\mathrm{AgGaGe}_{2} \mathrm{~S}_{2} \mathrm{Se}_{4}$, зумовлену структурними технологічними дефектами статичного характеру. Вважаючи домішкові центри однозарядними і використовуючи експериментально визначене значення $\Delta_{0}$, а також теоретичні формули, представлені в роботі [2] $\left(\Delta_{0}=2,2\left(n_{t} a_{B}^{3}\right)^{2 / 5} E_{B}\right)$, нами було оцінено концентрацію однозарядних точкових дефектів, відповідальних за розмиття смуги власного поглинання. Вона виявилася рівною $n_{t} \approx 10^{18}-2 \cdot 10^{18}$ $\mathrm{cm}^{-3}$. При цьому вважалося, що ефективна маса електрона в зоні провідності $m_{c} \approx 0,2 m_{0}\left(m_{0}\right.$ - маса вільного електрона), що справедливо для багатьох бінарних халькогенідних напівпровідників.

Тверді розчини $\mathrm{AgGaGe} \mathrm{S}_{2} \mathrm{Se}_{4}$ належать до монокристалів з дефіцитом атомів Ag у вузлах кристалічної гратки в позиції $16 b$ (про що повідомлялось вище). Це приводить до наявності в розчинах стехіометричних вакансій срібла $\left(V_{\mathrm{Ag}}\right)$, концентрація яких згідно з рентгеноструктурними дослідженнями становить $N \approx 10^{20} \mathrm{~cm}^{-3}$. Катіонні вакансії в халькогенідних сполуках відіграють роль акцепторів. Для багатьох бінарних халькогенідів групи $\mathrm{A}^{\mathrm{II}} \mathrm{B}^{\mathrm{VI}}$, зокрема, твердих розчинів $\mathrm{CdS}-\mathrm{CdSe}$, які є аналогами досліджуваних розчинів, енергетичне положення катіонних вакансій близьке до середини забороненої зони
$[6,7]$. Якщо це має місце для монокристалів розчинів $\mathrm{AgGaGe}_{2} \mathrm{~S}_{2} \mathrm{Se}_{4}$, то найбільш імовірним є припущення про зв'язок зони локалізованих станів біля середини забороненої зони розчину (яка прив'язує $E_{\mathrm{F}}$ ) з $V_{\mathrm{Ag}}$. Очевидно, акцепторним характером $V_{\mathrm{Ag}}$ зумовлений p-тип провідності монокристалів $\mathrm{AgGaGe} \mathrm{S}_{2} \mathrm{Se}_{4}$ і розмиття краю смуги власного поглинання світла.

Як зазначалось вище, за значення $\Delta_{0} \approx 0,07$ еВ відповідала концентрація однозарядних дефектів $n_{t} \approx 10^{18} \mathrm{~cm}^{-3}$, що менше концентрації стехіометрич-

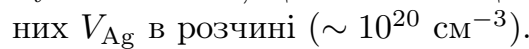

Очевидно, не всі стехіометричні вакансї $\mathrm{Ag}$ відіграють роль однозарядних акцепторів $V_{\mathrm{Ag}}^{-}$. Частина вакансій, взаємодіючи з різними структурними дефектами, на які багаті складні напівпровідникові сполуки, утворюють нейтральні комплекси, що не впливають на випадковий розподіл потенціалу електричного поля, зумовленого флуктуацією концентрації заряджених дефектів. Прикладом таких нейтральних комплексів можуть слугувати донорноакцепторні пари, акцептором в яких є вакансія $\mathrm{Ag}$, а роль донорів відіграють мілкі іонізовані дефекти $\left(V_{\mathrm{Ag}}^{-}-D^{+}\right)^{0}$, або скупчення $V_{\mathrm{Ag}}$. Такі дефекти можуть бути центрами швидкої рекомбінації, зменшуючи фоточутливість матеріалу і центрами поглинання та розсіювання світла, що збільшує коефіцієнт поглинання в області вікон пропускання світла, який в досліджуваних розчинах був рівним $K \approx 5-7 \mathrm{~cm}^{-1}$. Аналогічні явища спостерігались і в інших халькогенідних сполуках $[8,9]$.

Оцінена за енергією квантів $h \nu$ (для $K=350 \mathrm{~cm}^{-1}$ ) на КП оптична ширина забороненої зони при температурах 77 та $300 \mathrm{~K}$ виявилась рівною $E_{g 0} \sim 2,52$ еВ та $E_{g 0} \sim 2,39$ еВ відповідно, що узгоджується $з$ термічною шириною $E_{g T} \approx 2,28 \mathrm{eB}(T=300 \mathrm{~K})$, визначеною вище із залежності $\sigma(T)$.

На рис. 3 зображено зміну оптичної ширини забороненої зони із зміною температури. Розрахований нами термічний коефіцієнт зміни $E_{g}$ :

$\beta=\frac{E_{g 77}-E_{g 300}}{300-77}$

дорівнює $5,8 \cdot 10^{-4} \frac{\mathrm{eB}}{\mathrm{K}}$, що є характерним для більшості напівпровідників. Температурна залежність ширини забороненої зони твердих розчинів в інтервалі 77-300 K має лінійний характер (рис. 3):

$$
E_{g 0}=E_{g 77}-\beta(T-77 \mathrm{~K}) .
$$

На рис. 4 наведено спектральний розподіл фотопровідності монокристалів $\mathrm{AgGaGe}_{2} \mathrm{~S}_{2} \mathrm{Se}_{4}\left(I_{T}, I_{\Phi}-\right.$ 


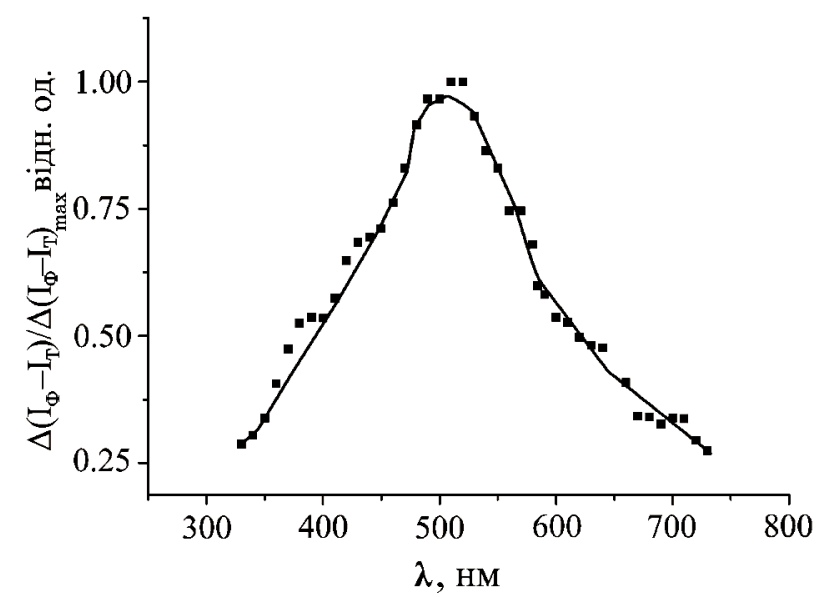

Рис. 4. Фотопровідність монокристалів $\mathrm{AgGaGe}_{2} \mathrm{~S}_{2} \mathrm{Se}_{4}$ при $T=$ $300 \mathrm{~K}$

значення струму в темноті і на світлі відповідно). Широкий максимум фотопровідності, який лежить в області КП, очевидно відповідає власній фотопровідності. Оцінена за максимумом $Ф П\left(\lambda_{m} \cong 0,563\right.$ нм) ширина забороненої зони твердого розчину при $T=300 \mathrm{~K}$ рівна $E_{g}=2,30 \mathrm{eB}$, що добре узгоджується зі значеннями оптичної $\left(E_{g 0}=2,39 \mathrm{eB}\right)$ і термічної $\left(E_{g t}=2,28 \mathrm{eB}\right)$ ширини забороненої зони твердого розчину при $T=300 \mathrm{~K}$. Кратність зміни електропровідності в максимумі при освітленості $10^{2}$ лк становила $\approx 2$. Мала фоточутливість монокристалів $\mathrm{AgGaGe} \mathrm{S}_{2} \mathrm{Se}_{4}$, в порівнянні з їх бінарними аналогами, очевидно, зумовлена наявністю великої концентрації центрів швидкої рекомбінації, які, зазвичай, зв'язані з структурними дефектами кристалічної гратки, що підтверджується великою півшириною $(\approx 230$ нм) піка власної фотопровідності (рис. 4 )

\section{3. Висновки}

Таким чином, тверді розчини $\mathrm{AgGaGe}_{2} \mathrm{~S}_{2} \mathrm{Se}_{4}$ належать до дефектних напівпровідників 3 розподілом електронних енергетичних станів $(N(E))$, який добре підтверджує модель Девіса і Мотта з вузьким максимумом $(\Delta \approx 0,1 \mathrm{eB})$ локалізованих станів біля середини забороненої зони (рис. 1,б). Встановлено ширину забороненої зони твердого розчину.

Маючи високу термостійкість і енергію активації електропровідності ( $E=1,14 \mathrm{eB})$ кристали $\mathrm{Ag}$ $\mathrm{GaGe}_{2} \mathrm{~S}_{2} \mathrm{Se}_{4}$ можуть бути перспективним матеріалом різних термодатчиків і термісторів, призначених для функціонування в області температур близьких до кімнатної.
Будучи фоточутливими i радіаційно стійкими, $\mathrm{AgGaGe}_{2} \mathrm{~S}_{2} \mathrm{Se}_{4}$ мають перспективу знайти застосування в електронних і оптоелектронних приладах, що використовуються в середовищах з підвищеною ядерною радіацією.

1. M.V. Shevchuk, V.V. Atuchin, A.V. Kityk, A.O. Fedorchuk, Y.E. Romanyuk, S. Calus, O.M. Yurchenko, and O.V. Parasyuk, J. Cryst. Growth 318, 708 (2011).

2. В.Л. Бонч-Бруевич, И.П. Звягин, Р. Кайпер и др., Электронная теория неупорядоченных полупроводников (Наука, Москва, 1981).

3. Л.С. Стильбанс, Физика полупроводников (Советское радио, Москва, 1967).

4. Н. Мотт, Э. Дэвис, Электронные процесы в некристаллических веществах (Мир, Москва, 1974).

5. Н.А. Вайнштейн, А.Ф. Зацепин, В.С. Кортов, Ю.В. Щапова, Физ. твер. тела 42, 224 (2000).

6. Физика и химия соединений $A^{\mathrm{II}} B^{\mathrm{VI}}$ (под ред. С. А. Медведева) (Мир, Москва, 1970).

7. В.Е. Лашкарев, А.В. Любченко, М.К. Шейнкман, Неравновесные процессы в ботопроводниках (Наукова думка, Киев, 1981).

8. Г.Є. Давидюк, А.П. Третяк, В.В. Божко, В.В. Булатецький, О.В. Парасюк, Наук. вісн. Волин. нац. у-ту ім. Лесі Українки. Фіз. науки, 6, 28 (2010).

9. В.В Божко, Л.В. Булатецька, Г.Є. Давидюк, О.В. Парасюк, В.П. Сачанюк, А.П. Третяк, УФЖ 55, 208 (2010).

Одержано 06.09.11

\section{ЭЛЕКТРИЧЕСКИЕ И ОПТИЧЕСКИЕ СВОЙСТВА МОНОКРИСТАЛЛОВ $\mathrm{AgGaGe}_{2} \mathrm{~S}_{2} \mathrm{Se}_{4}$}

Г.Л. Мирончук, Г.Е. Давыдюк, О.В. Парасюк, М.В. Шевчук, Е.В. Якимчук, С.П. Данылъчук

Р е з ю м е

В работе исследовались монокристаллы твердых растворов 50 мол.\% $\mathrm{AgGaGeS} 4+50$ мол.\% $\mathrm{AgGaGe}_{3} \mathrm{Se}_{8}$. Вследствие статистического размещения в узлах кристаллической решетки атомов $\mathrm{Ga}$ и $\mathrm{Ge}$, а также, наличия узлов, не заполненных атомами $\mathrm{Ag}$, твердые растворы проявляют свойства неупорядоченных полупроводников с максимальной плотностью локализованных энергетических состояний около середины запрещенной зоны. Установлена оптическая и термическая ширина запрещенной зоны и их температурная зависимость $\left(E_{g} \approx 2,30\right.$ эВ при $T \approx 300 \mathrm{~K})$. Монокристаллы $\mathrm{AgGaGe}_{2} \mathrm{Se}_{4}$ являются фоточувствительными полупроводниками $p$-типа проводимости с положением уровня Ферми около середины запрещенной зоны. Исследованы особенности электропроводности и спектрального распределения фотопроводимости. Предложена непротиворечивая физическая модель, позволяющая объяснить экспериментально полученные результаты. 


\section{ELECTRICAL AND OPTICAL PROPERTIES \\ OF $\mathrm{AgGaGe}_{2} \mathrm{~S}_{2} \mathrm{Se}_{4}$ SINGLE CRYSTALS}

G.L. Myronchuk, G.E. Davyduk, O.V. Parasiuk, M.V. Shevchuk, O.V. Jakymchuk, S.P. Danyl'chuk

Lesya Ukrainka Volyn National University

(13, Volya Ave., Luts'k 43025, Ukraine;

e-mail: g_muronchuk@ukr.net)

$\mathrm{S} u \mathrm{~m}$ m a r y

Single crystals of the solid solution 50 mol. $\% \mathrm{AgGaGeS}_{4}+$ 50 mol.\% $\mathrm{AgGaGe}_{3} \mathrm{Se}_{8}$ are studied. Due to a statistical dis- tribution of $\mathrm{Ga}$ and $\mathrm{Ge}$ atoms over the relevant crystal lattice sites and the presence of vacancies at $\mathrm{Ag}$ sites, the solid solution exhibits properties of disordered semiconductors with the maximum density of localized energy states near the middle of the energy gap. The optical and thermal bandgap energies, as well as their temperature dependences, have been determined $\left(E_{g} \approx 2.30 \mathrm{eV}\right.$ at $\left.T \approx 300 \mathrm{~K}\right) . \mathrm{AgGaGe}_{2} \mathrm{Se}_{4}$ single crystals are found to be photosensitive $p$-type semiconductors with the Fermi level locating near the middle of the bandgap. The peculiarities in the conductivity of the samples and the spectral distribution of their photoconductivity have been examined. A consistent physical model that explains the experimental results has been suggested. 